\title{
Perancangan Sistem Transaksi Non-Tunai Berbasis QR Code di Platform Android
}

\author{
Jay Idoan Sihotang ${ }^{1}$, Rawlson Yoshua Limbong ${ }^{2}$ \\ 1,2Fakultas Teknologi Informasi, Universitas Advent Indonesia \\ e-mail: 1*jay.sihotang@unai.edu, 21681009@unai.edu
}

\begin{abstract}
Abstrak
Dewasa ini perkembangan teknologi mempengaruhi berbagai aspek dalam kehidupan, termasuk dalam melakukan transaksi finansial. Di kampus Universitas Advent Indonesia, pembayaran masih menggunakan cara konvensional alias menggunakan uang kertas untuk pembayaran. Sehingga memungkinkan terjadinya kesalahan dalam pembayaran, maupun pengguna tidak bisa melacak history pembayaran yang dilakukan. Sistem informasi dalam bentuk aplikasi pembayaran yang dibangun diharapkan dapat menjadi alternatif pembayaran di kampus. Aplikasi pemrograman bergerak yang dibangun berdasarkan Analisa kebutuhan terhadap sistem lama, dan dibangun menggunakan Android dengan database menggunakan firebase. Proses pembayaran menggunakan validasi $Q R$ Code, baik untuk melakukan transaksi antar penjual dengan pengguna, maupun sesama pengguna. Hasil dari penelitian adalah sebuah aplikasi pembayaran berbasis $Q R$ Code yang dapat berjalan dengan baik dan teruji secara fungsional dan tampilannya.
\end{abstract}

Kata Kunci: Pemrograman Bergerak, Sistem Informasi, Aplikasi Pembayaran, QR Code, Android

\section{The Design of QR Code Based Cashless Transaction System on Android Platform}

\begin{abstract}
Nowadays the development of technology affects many aspects in life, including financial transaction. In Universitas Advent Indonesia, the payment still using conventional method alias using cash for payments. That causes some possibility of error on payments, and the users can't trace their payments history. The information system in a form of payment application is expected to become a payments alternative in campus. The mobile programming application was developed based on old system requirement analysis and developed using Android with Firebase as a database. The payment process is validated using $Q R$ Code, both to make transactions between sellers and users, as well as fellow users. The results of the study are a QR Code-based payment application that can run well and is tested both functionally and in appearance.
\end{abstract}

Keywords: Mobile programming, Information System, Payment Application, QR Code, Android

\section{Pendahuluan}

Dewasa ini perkembangan teknologi Informasi sangat pesat dan mempengaruhi banyak aspek dalam kehidupan manusia. Salah satu dari penggunaan teknologi informasi tersebut adalah dalam melakukan sistem pembayaran. Sesuai dengan definisinya, maka aplikasi/sistem yang dibangun bertujuan untuk mendukung dan mempermudah pengolahan atau transmisi informasi antar berbagai pihak [1] [2]. Di Universitas Advent Indonesia (UNAI), sistem pembayaran dari mahasiswa/staf/dosen kepada merchant /vendor masih menggunakan metode konvensional alias menggunakan uang tunai. $\mathrm{Di}$ mana memungkinkan adanya terjadi ketidakselarasan nominal transaksi, kesulitan ketika mengembalikan uang 
kembalian, maupun pembeli tidak dapat mengetahui riwayat transaksi yang sudah dilakukan. Maka dibutuhkan sebuah sistem yang dapat mencegah kesalahan dalam pencatatan atau perhitungan dalam membuat laporan keuangan [3]. Aplikasi yang dibangun dapat memudahkan transaksional antar penjual dan pembeli, dan diharapkan dapat menjadi alternatif transaksi finansial [4]. Dengan adanya sistem pembayaran ini, maka diharapkan pengguna tidak perlu lagi melakukan pencatatan secara manual dan hasil dari transaksi dapat dilihat secara langsung.

Pada sistem lama seluruh transaksi masih dilakukan secara manual. Manual yang dimaksud adalah seluruh pencatatan dan pembayaran dilakukan tidak menggunakan sistem yang terintegrasi langsung ke Universitas Advent. Sebagai contoh catatan masih dilakukan secara tertulis di buku dan setiap laporan masih diantar ke Biro Keuangan Mahasiswa. Untuk penjelasan detailnya, bisnis yang di analisa adalah Laundry, Fotokopi, Bakery, OMI, Klinik. Secara umum, semua pembayaran dilakukan secara manual seperti menotalkan berapa biaya yang diberikan oleh kasir/pemilik, lalu membayarnya, memberikan bukti pembayaran dan mencatat transaksi yang dilakukan. Namun setiap departemen tidak memiliki alur yang sama. Hal inilah yang menyebabkan data yang ingin dimasukkan, mungkin tidak dicatat dengan baik atau laporan kurang lengkap

Aplikasi yang dibangun di atas sistem operasi Android menggunakan PHP sebagai backend yang memungkinkan terjadinya pertukaran data yang terintegrasi antara aplikasi dengan basis data [5]. Aplikasi mobile digunakan oleh lebih banyak pengguna, dan sistem operasi Android diyakini mumpuni dan aman [6] [7]. Penelitian ini menggunakan manajemen basis data firebase yang memungkinkan terjadinya pertukaran data secara real-time [8]. Dan untuk aplikasi mobile, sudah teruji bahwa database Firebase memiliki tingkat respon real-time yang lebih tinggi [9]. Dan penggunaan $Q R$ Code sebagai validator transaksi antara penjual dengan pembeli maupun antara sesama pengguna dikarenakan $Q R$ Code mampu menampung ukuran data yang lebih besar [10]. Pengembangan aplikasi pembayaran ini diharapkan dapat menjadi alternatif pembayaran di kampus, dan juga teruji secara fungsionalitas maupun tampilannya.

\section{Metode Penelitian}

Penelitian ini menggunakan metode Waterfall yang bersifat linear. Yaitu pengembangan aplikasi dimulai dari tahap perancangan sampai dengan tahap publikasi sebagai akhir dari pengembangan [11] [12]. Kebutuhan sistem yang dirancang bertujuan untuk memenuhi kebutuhan pengguna untuk dapat melihat saldo, melakukan transaksi, melakukan transfer, dan melihat riwayat transaksi. Aplikasi yang dibangun menggunakan perangkat keras Intel Core i7 dengan RAM 16GB, dan lingkungan pengembangan aplikasi menggunakan Android Studio, dan dibantu dengan Visual Studio Code. Aplikasi dibangun dengan API Level Android di level 22, dengan tujuan agar banyak orang yang dapat menggunakannya.

\section{Use Case Diagram}

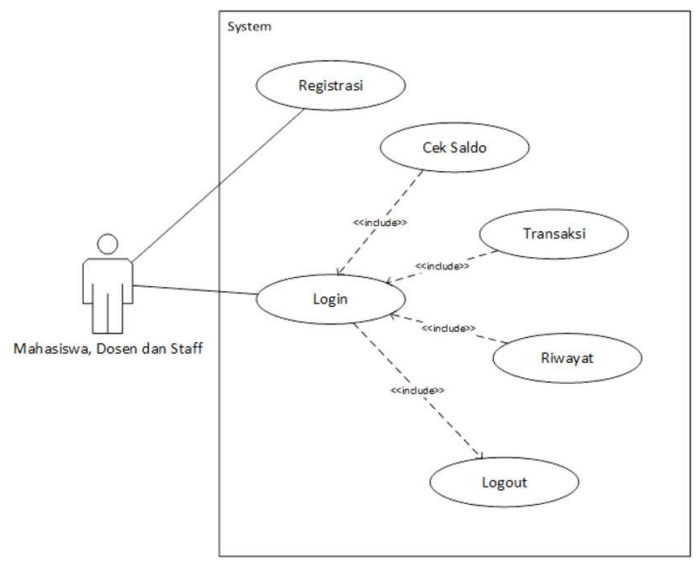

Gambar 1 Use Case Diagram 
Perancangan Sistem Transaksi Non-Tunai Berbasis QR Code di Platform Android

Gambar 1 menggambarkan interaksi antar pengguna dengan fungsi dalam aplikasi tersebut. Sistem baru akan mencangkup beberapa fungsi. Di antaranya, fungsi register yang berguna untuk mendaftarkan pengguna, fungsi login yang memungkinkan pengguna masuk ke dalam aplikasi, fungsi cek saldo yang memberi informasi mengenai saldo yang dimiliki pengguna, fungsi transaksi untuk melakukan transaksi antara pengguna dengan vendor/penjual, fungsi transfer yang memungkinkan sesama pengguna saling bertukar atau transfer saldo, dan fungsi riwayat yang menampilkan informasi dari transaksi atau transfer yang dilakukan oleh pengguna.

\section{Activity Diagram}

Activity Diagram berguna untuk memodelkan interaksi antara pengguna dengan fungsi-fungsi yang ada secara bertahap. Dalam pengembangan aplikasi ini, terdapat beberapa Activity Diagram yaitu dalam kegiatan registrasi, login, cek saldo, transfer, transaksi, dan cek riwayat transaksi.

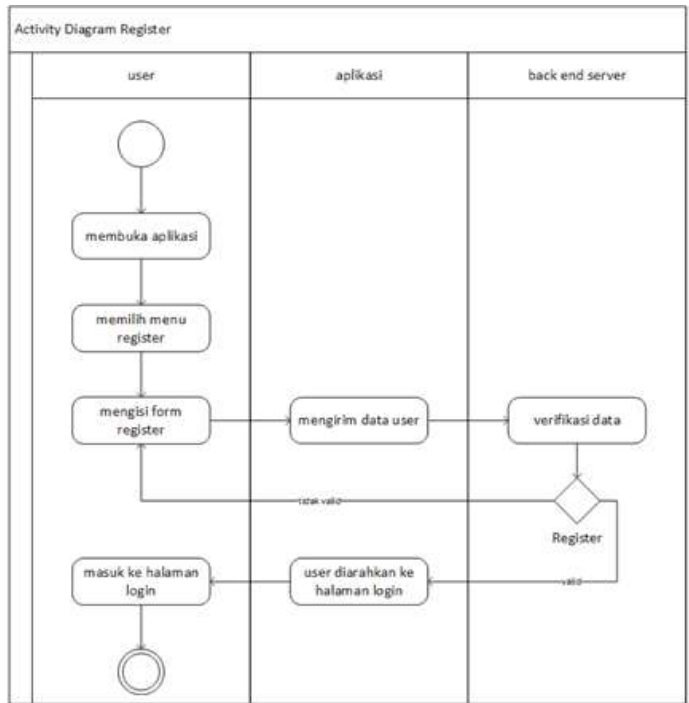

Gambar 2 Activity Diagram Registrasi

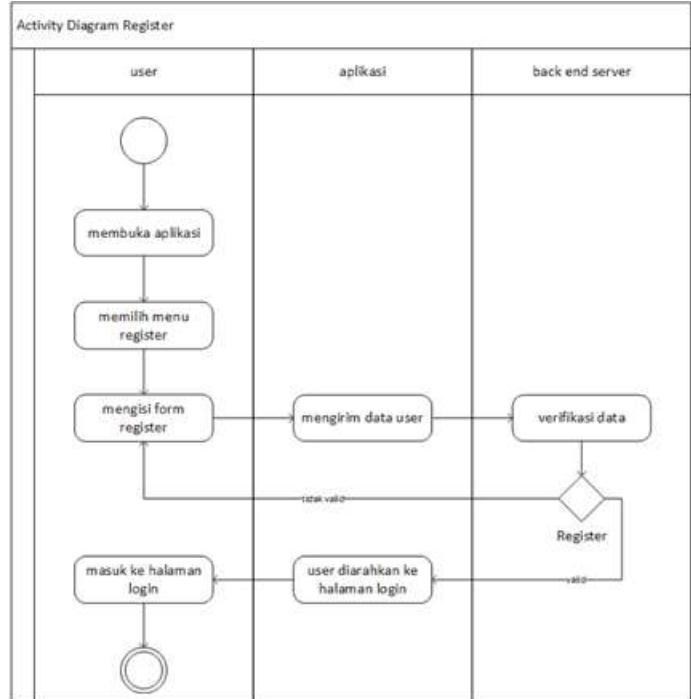

Gambar 3 Activity Diagram Login

Gambar 2 menjelaskan langkah-langkah yang harus dilakukan oleh pengguna sebelum dapat menggunakan aplikasi. Pengguna diharuskan untuk memiliki akun, dan pengguna dapat melakukan registrasi dengan memilih menu registrasi. Kemudian memasukkan data-data yang terdapat dalam form. Ketika data sudah selesai dimasukkan dan divalidasi oleh aplikasi, maka pengguna akan diarahkan ke halaman login. Namun ketika ditemukan suatu kesalahan/kekurangan dalam pengisian form registrasi, maka akan ditampilkan notifikasi error.

Activity Diagram Login (Gambar 3) menjelaskan mengenai tahapan yang dijalankan untuk memvalidasi apakah pengguna sudah memasukkan data username dan password yang benar. Jikalau ditemukan kesalahan dalam informasi yang dimasukkan, maka pengguna kembali diarahkan ke halaman login. Namun jikalau data yang dimasukkan benar, maka pengguna akan diarahkan ke halaman utama.

Di halaman utama, pengguna dapat berinteraksi dengan beberapa fungsi. Salah satunya adalah cek saldo. Di mana pengguna dapat melihat berapa sisa saldo yang dimiliki untuk dapat melakukan transaksi dengan penjual atau melakukan transfer dengan sesama pengguna. Mekanisme fungsi cek saldo diilustrasikan dalam Gambar 4 di bawah ini. 


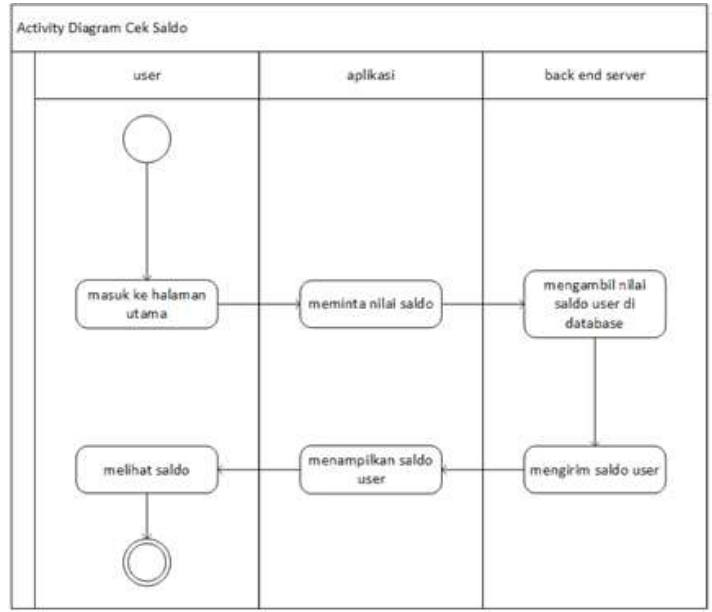

Gambar 4 Activity Diagram Cek Saldo

Terdapat dua buah role yang akan dilakukan oleh pengguna dalam menjalankan fungsi transfer yaitu sebagai pemberi atau sebagai penerima. Sebagai penerima, pengguna akan memilih menu transfer dan diarahkan ke halaman yang berisikan $Q R$ Code dari pengguna sebagai penerima, lalu menunjukkan $Q R$ Code tersebut kepada pengirim. Sebagai pengirim, pengguna akan memilih menu transfer dan tekan tombol next, kemudian akan masuk ke halaman transfer. Pengguna yang berperan sebagai pengirim memasukkan nominal yang akan dikirim, kemudian menekan tombol scan barcode untuk memindai $Q R$ Code dari penerima dana. Setelah memindai $Q R$ Code dari penerima, pengguna yang berperan sebagai pengirim menekan tombol konfirmasi untuk melakukan transfer. Secara otomatis sistem akan mencatat transaksi yang dilakukan, mengirimkan dana dari pengirim ke penerima, dan memberi informasi bahwa transfer yang dilakukan telah berhasil. Gambar 5 di bawah ini menggambarkan mekanisme transfer dana dari pengirim ke pengguna.

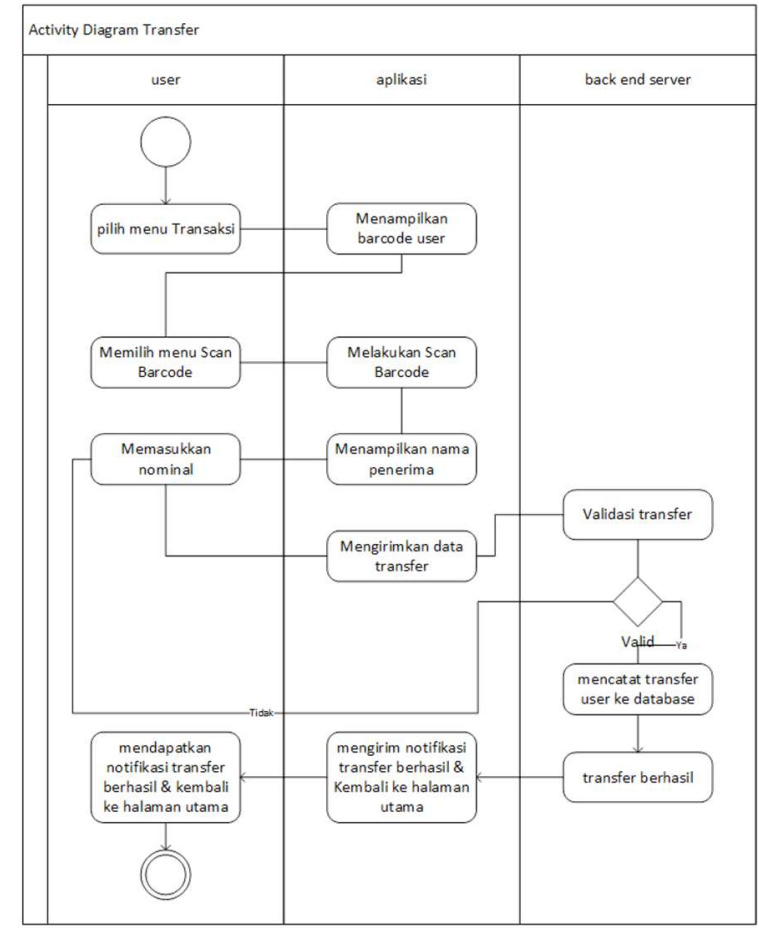

Gambar 5 Activity Diagram Transfer Dana

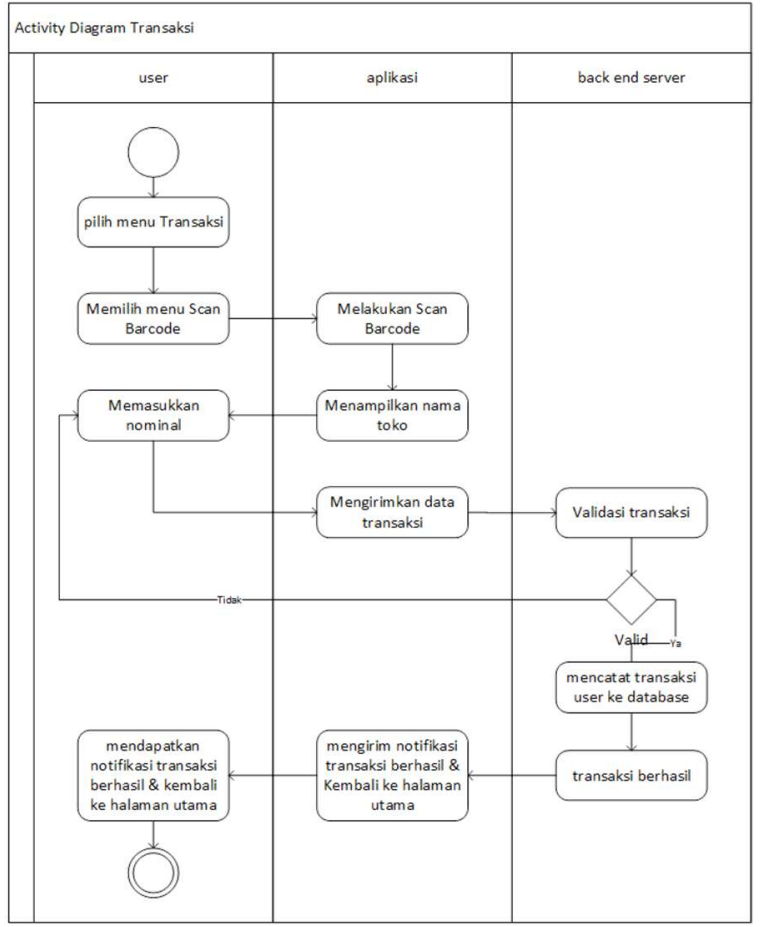

Gambar 6 Activity Diagram Transaksi 
Gambar 6 mengilustrasikan mekanisme transaksi antara pengguna dengan penjual. Di mana untuk melakukan fungsi transaksi antara pengguna dengan penjual, pengguna dapat memilih menu transaksi di halaman utama. Kemudian pengguna akan diarahkan ke halaman yang berisikan form nominal yang akan dikirim. Untuk dapat memvalidasi pembayaran ke penjual, pengguna harus menekan tombol scan barcode yang membuka sebuah jendela pemindai yang digunakan untuk memindai $Q R$ Code dari penjual. Setelah $Q R$ Code penjual sudah dipindai dan nominal sudah dimasukkan oleh pengguna, makan pengguna perlu menekan tombol konfirmasi untuk melakukan transaksi. Aplikasi akan mengirimkan dana dari pengirim ke penjual, dan mencatat transaksi yang dilakukan. Pengguna akan mendapatkan notifikasi bahwa transaksi yang dilakukan berhasil.

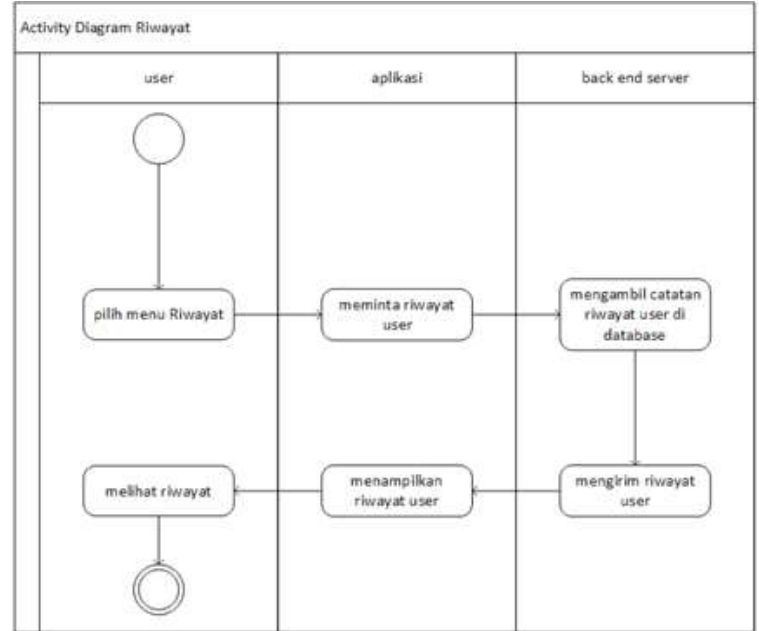

Gambar 7 Activity Diagram Cek Riwayat

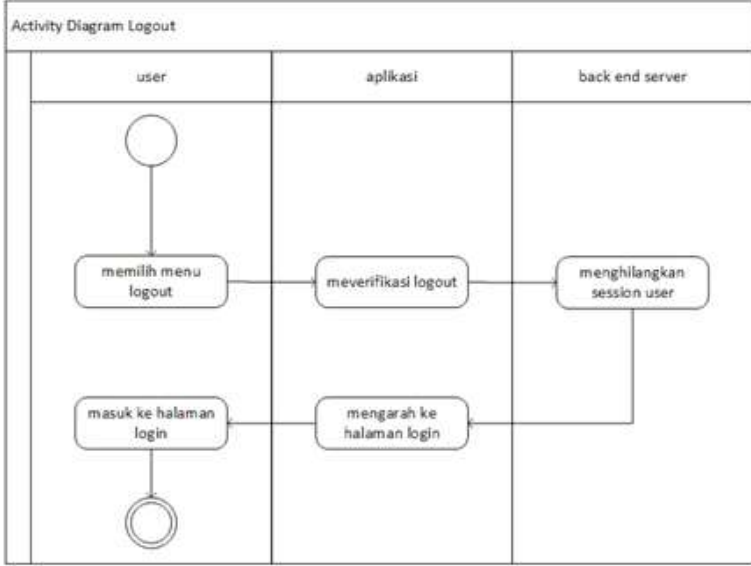

Gambar 8 Activity Diagram Logout

Pengguna dapat mengetahui riwayat transaksi/transfer yang dilakukan oleh pengguna dengan memilih menu riwayat pada halaman utama. Kemudian pengguna akan ditampilkan seluruh transaksi/transfer yang pengguna telah lakukan. Activity Diagram cek riwayat diilustrasikan dalam Gambar 7. Setelah pengguna selesai menggunakan aplikasi, pengguna dapat menjalankan fungsi logout sebagaimana diilustrasikan dalam Gambar 8. Pengguna akan memilih menu logout dari halaman utama, dan kemudian aplikasi akan memverifikasi logout dan menghapus sesi aktif dari pengguna. Pengguna akan kembali diarahkan ke halaman login.

\section{Perancangan Database Firebase}

Untuk dapat mengakses database firebase, dibutuhkan sebuah autentikasi terhadap pengguna yang aktif dalam sistem [13]. Data pengguna yang disimpan berupa identifier yang menjabarkan kapan pengguna melakukan registrasi, waktu terakhir login, serta UID dari pengguna. Dalam aplikasi ini autentikasi berguna untuk mengetahui apakah pengguna sudah terdaftar atau belum.

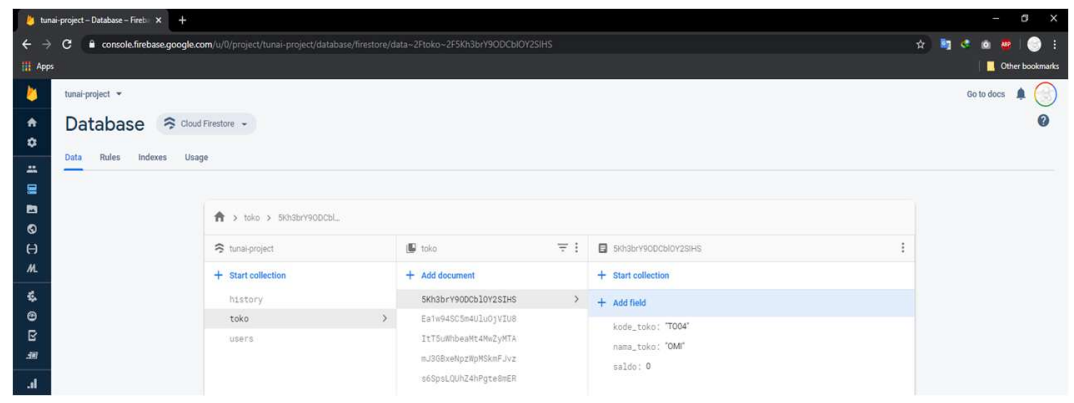

Gambar 9 Struktur Database Firebase 
Database yang digunakan dalam penelitian ini adalah Cloud Firestore yang merupakan database nonSQL, dan dapat diakses di mana saja selama memiliki koneksi internet. Database ini menyimpan keseluruhan data dari aktivitas maupun entitas yang ada di dalam aplikasi. Mulai dari data pengguna, data toko, dan juga riwayat transaksi yang dilakukan di dalamnya.

\section{Perancangan Antarmuka}

Perancangan Antarmuka (User Interface / UI) bertujuan untuk menggambarkan bagaimana tampilantampilan yang ada dalam aplikasi dimulai dari Halaman selamat datang sampai dengan menu di dalamnya. Tujuan ini dibuat agar dapat mempermudah pembaca mengerti tampilan aplikasinya.

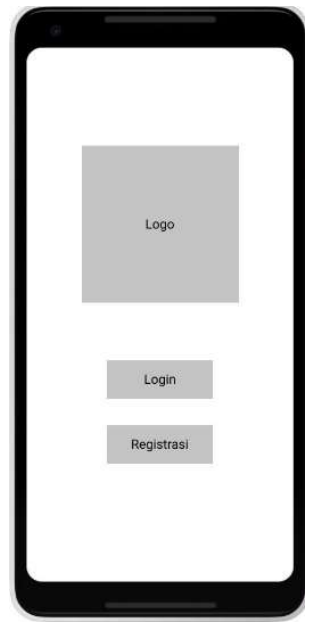

Gambar 9 Perancangan Antarmuka Selamat Datang

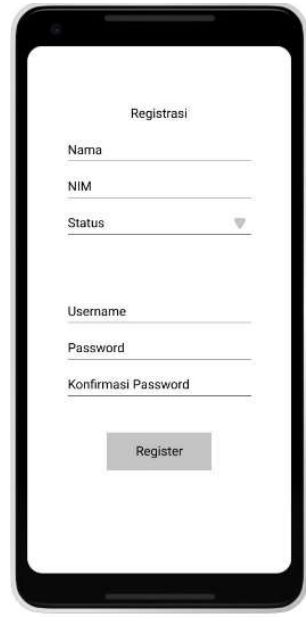

Gambar 10 Perancangan Antarmuka Registrasi

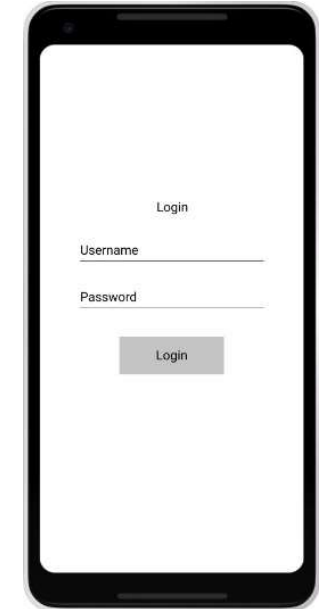

Gambar 11 Perancangan Antarmuka Login

Pada bagian Selamat Datang (Gambar 9), user dapat memilih menu yang telah di tampilkan seperti login dan registrasi. Jika user belum pernah memakai atau terdaftar, makau user harus melakukan Registrasi. Jika user sudah terdaftar, maka user memilih tombol login. Ketika user memilih tombol registrasi, user harus mengisi form yang telah disediakan. Jika sudah terisi, maka user dapat menekan tombol Register untuk meng-submit form yang telah diisi. Sebagaimana diilustrasikan pada Gambar 10.

Gambar 11 mengilustrasikan halaman login yang muncul setelah user selesai melakukan registrasi. user harus mengisi bagian username dan password untuk masuk ke dalam Aplikasi. Jika sudah diisi oleh user, maka user dapat menekan tombol login untuk masuk ke dalam aplikasi.

Pada halaman Utama (Gambar 12), di dalam tampilan ini akan ada nama user, nomor induk, dan saldo dari user. Selain informasi user ada juga tombol seperti transaksi, transfer, riwayat, dan logout. User akan diarahkan ke halaman Transaksi (Gambar 13) setelah menekan tombol transaksi. Pada bagian ini, user dapat membuka scanner $Q R$ Code dan juga melakukan input nilai dari pembayaran yang akan dibayar. Setelah itu, user dapat menekan tombol konfirmasi untuk melakukan pembayaran. 


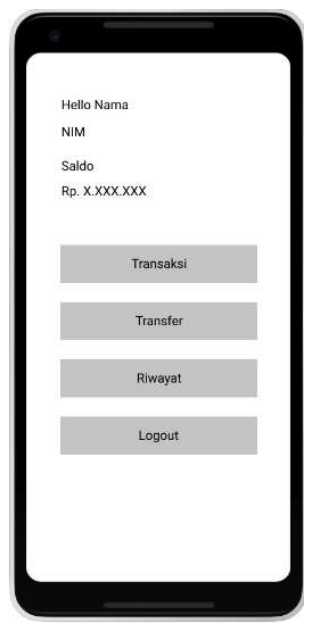

Gambar 12 Perancangan Antarmuka Halaman Utama

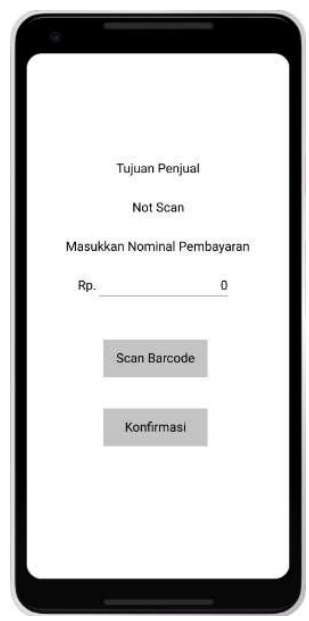

Gambar 13 Perancangan Antarmuka Transaksi

User dapat memilih tombol Transfer untuk melakukan transfer ke sesama user dan diarahkan ke halaman menu transfer (Gambar 14). Pada bagian ini, user dapat melihat $Q R$ Codeyang dibuat oleh aplikasi dan selain itu tujuan dari $Q R$ Code yang ditampilkan oleh aplikasi bertujuan untuk menerima transferan dari user yang akan mengirim ke penerima. Selain itu pengirim dapat menekan tombol next untuk masuk ke halaman selanjutnya. Dan tombol back bertujuan untuk balik ke halaman sebelumnya. Setelah menekan tombol next, user pengirim akan mengarahkan $Q R$ Codenya ke barcode penerima yang ada pada menu transfer dan setelah itu memasukkan berapa nominal yang akan ditransfer. Setelah melakukan input, maka user dapat menekan tombol konfirmasi untuk melakukan transfer. Ilustrasi halaman transfer terdapat pada Gambar 15. Pengguna dapat melihat riwayat dengan menekan tombol riwayat pada halaman utama, dan diarahkan ke halaman Riwayat (Gambar 16). Pada bagian ini, user dapat melihat riwayat seperti pembayaran ke toko/vendor mana dan transfer ke user lain. Tombol back bertujuan untuk kembali ke halaman utama.

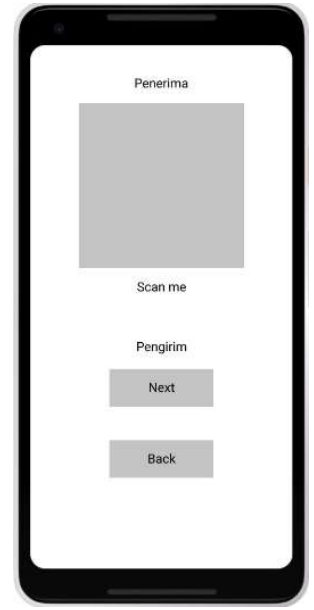

Gambar 14 Perancangan Antarmuka Menu Transfer

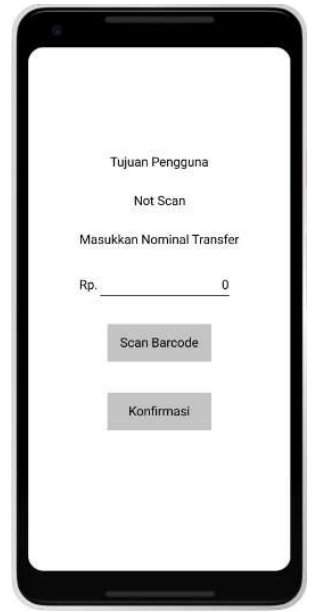

Gambar 15 Perancangan Antarmuka Transfer

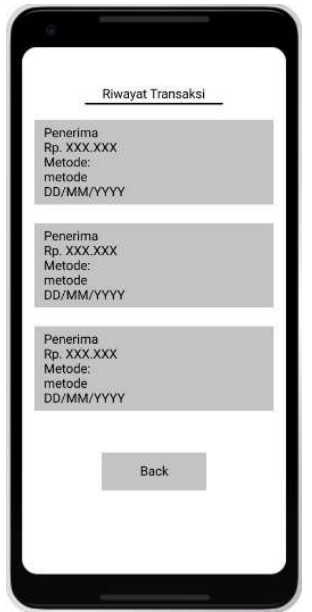

Gambar 16 Perancangan Antarmuka Riwayat 


\section{Hasil dan Pengujian Sistem}

Saat pertama kali aplikasi dibuka, pengguna akan dihadapkan di halaman selamat datang (Gambar 17) dengan pilihan untuk login atau register. Jika pengguna pertama kali menggunakan aplikasi ini, maka diwajibkan untuk menekan tombol register untuk mendaftar. Jika pengguna sudah pernah menggunakan ini, maka pengguna dapat menekan tombol login untuk masuk ke dalam aplikasi.

Ketika usermemilih tombol register, pengguna akan mengisi form yang bertujuan untuk mendaftarkan diri ke dalam sistem di halaman registrasi (Gambar 18). Ada beberapa hal yang perlu di isi seperti nama, username dan lain sebagainya. Setelah meng-inputdata, maka pengguna dapat menekan tombol Registrasi untuk mendaftar dan akan diarahkan ke halaman login. Ketika masuk di halaman login (Gambar 19), pengguna akan dihadapkan dengan form login. Halaman login bertujuan untuk mengautentikasi pengguna yang akan masuk ke dalam sistem. Setelah pengguna memasukkan username dan password, maka aplikasi akan mencek apakah pengguna sudah terdaftar atau belum. Jika salah satu dari username atau password yang di-input tidak terdaftar atau tidak sesuai dengan yang ada di dalam database, maka aplikasi akan tetap di halaman login. Namun, jika username dan password benar, maka pengguna akan masuk ke dalam halaman utama.

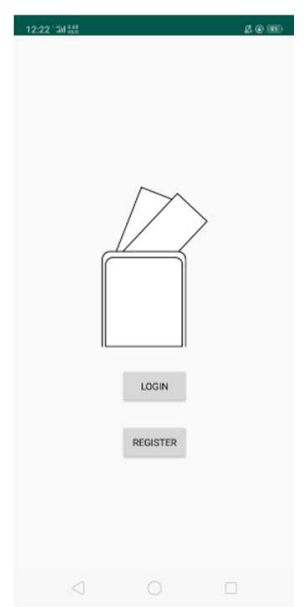

Gambar 17 Halaman Selamat Datang

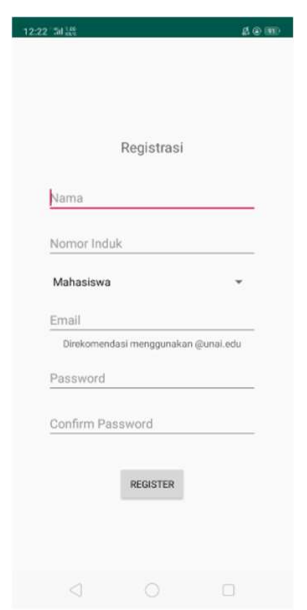

Gambar 18 Halaman Registrasi
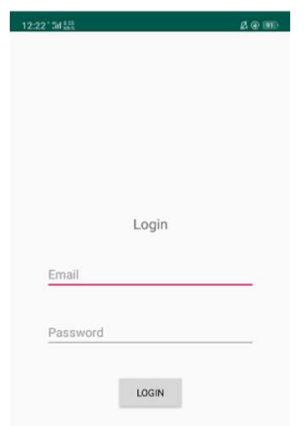

Gambar 19 Halaman Login

Halaman utama (Gambar 20) ditampilkan setelah pengguna masuk ke dalam sistem melalui halaman login. Halaman ini berisikan menu seperti transaksi, transfer, riwayat dan logout. Selain itu, pada tampilan ini akan ditampilkan saldo pengguna.

Ketika pengguna menekan tombol transaksi, pengguna akan diarahkan ke halaman transaksi (Gambar 21). Pada halaman ini, user dapat melakukan scan $Q R$ Code dari toko yang di inginkan. Setelah melakukan scan maka user harus meng-input berapa nilai yang nominal yang harus dibayar untuk melakukannya. Nominal akan diberikan oleh penjual untuk. Setelah itu, user dapat menekan tombol konfirmasi dan user akan diarahkan ke halaman utama. 

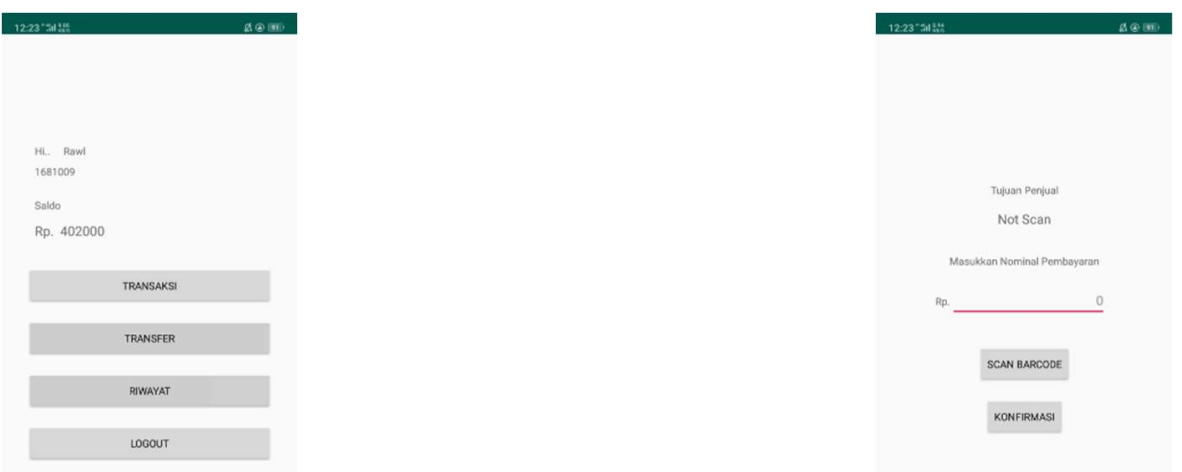

Gambar 20 Halaman Utama

Gambar 21 Halaman Transaksi

Dan pengguna dapat melakukan transfer dana antar sesama pengguna dengan menekan tombol transfer pada halaman utama, dan pengguna akan diarahkan ke halaman menu transfer (Gambar 22). Pada bagian ini, user akan ditampikan sebuah $Q R$ Code yang telah dibuat oleh aplikasi. Barcode tersebut berasal dari database dan di bentuk oleh aplikasi untuk di tampilkan. Selain $Q R$ Code yang telah dibuat oleh aplikasi, ada tombol next yang bertujuan untuk ke menu selanjutnya dari transfer. Dan juga tombol back untuk kembali ke halaman sebelumnya. Dan pada halaman transfer (Gambar 23) yang muncul setelah pengguna menekan tombol next pada menu transfer, data yang ditampilkan tidak banyak yang berbeda dengan tampilan di halaman transaksi, perbedaan dari halaman transfer ini digunakan untuk melakukan transfer ke sesama user. Jadi jika di gunakan ke toko, maka aplikasi tidak menerima barcode toko. Pengguna dapat melihat riwayat transaksi di menu transaksi dengan cara menekan tombol riwayat, dan aplikasi akan mengarahkan tampilan ke halaman riwayat (Gambar 24).
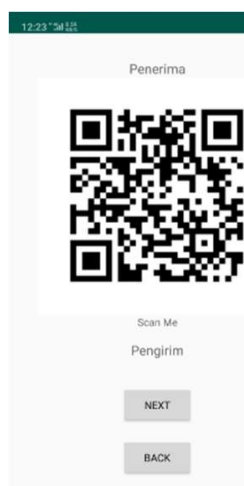

Gambar 22 Halaman Menu Transfer
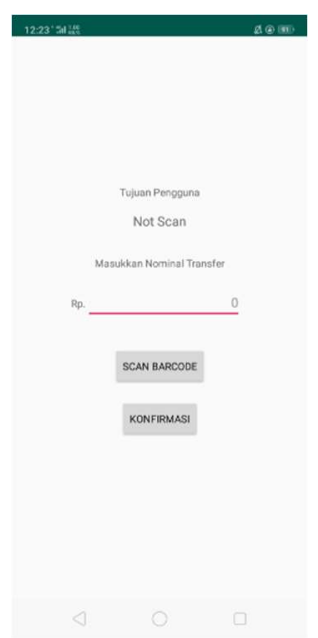

Gambar 23 Halaman Transfer

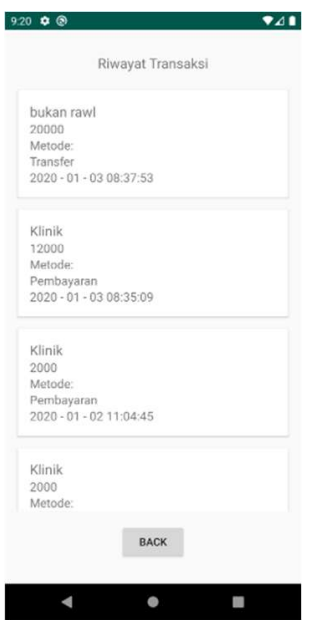

Gambar 24 Halaman Riwaya

\section{Application Programming Interface (API)}

Aplikasi ini menggunakan beragam Application Programing Interface (API) untuk membuatnya berjalan dengan baik. Sebagai contoh autentikasi dan database-nya. Karena aplikasi berjalan dalam sistem 
Android maka bahasa yang digunakan adalah Java. Firebase memberikan bagaimana cara menggunakan $A P I$ yang siap digunakan oleh pengembang untuk membuat aplikasi.

APIyang akan digunakan untuk autentikasi ada beberapa dimulai dari registrasi, login dan juga selama berada dalam aplikasi. Berikut contoh - contoh dari inti penggunaannya.

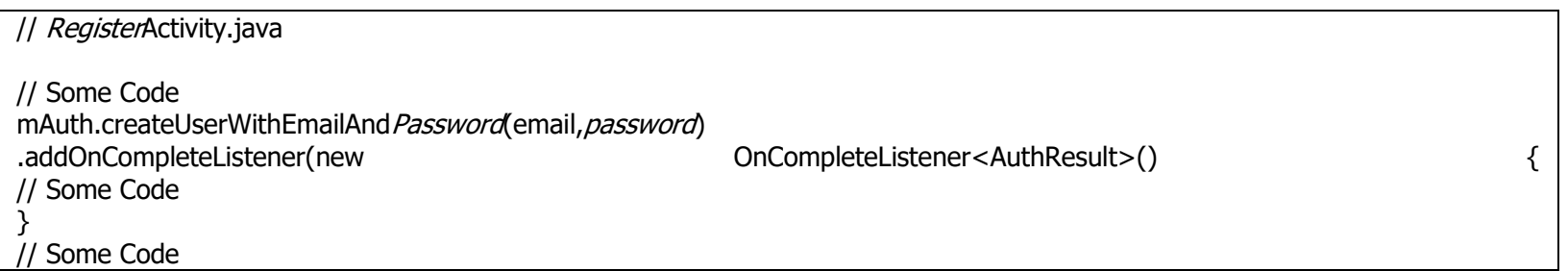

Pada bagian ini, $A P I$ yang digunakan bertujuan untuk melakukan registrasi yang akan dicatat dalam Authentication yang disediakan oleh Firebase. Dengan menggunakan kata kunci "createUserWithEmailAndPassword()" maka pengguna yang akan terdaftar akan dicatat seperti Identifier, Providers, Created, Signed In dan User UID. Namun pada bagian Signed In tidak akan ada nilai yang dicatat karena pengguna belum melakukan login. Jika pengguna sudah terdaftar, maka API akan memberikan respon bahwa pengguna yang lain sudah menggunakan Identifier yang sama, atau gagal mengirimkan data dan lain sebagainya.

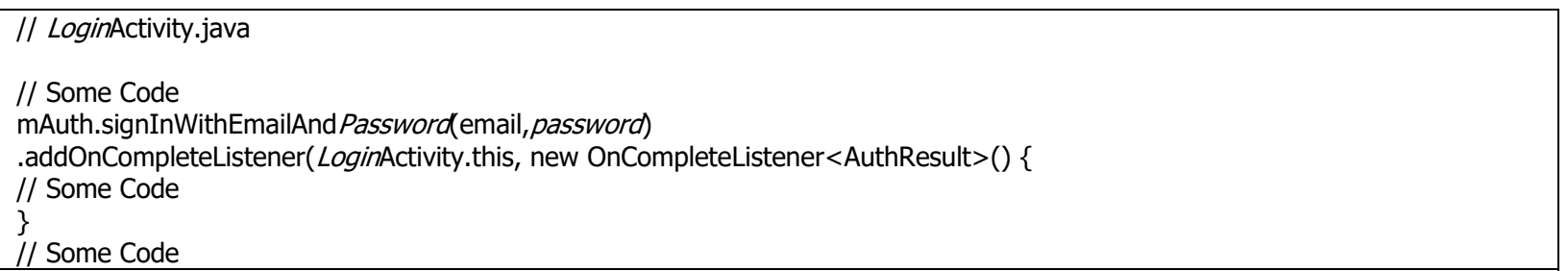

Pada bagian ini, $A P I$ yang digunakan bertujuan untuk melakukan login yang akan dicek dalam Authentication yang disediakan oleh Firebase. Dengan menggunakan kata kunci "signInWithEmailAndPassword()" Jika pengguna sudah terdaftar, maka pada bagian Signed In, akan dimasukkan data kapan pengguna telah berhasil melakukan login. Namun jika ada kesalahan, maka API akan memberikan respon seperti sedang offline, kesalahan email atau password dan lain sebagainya.

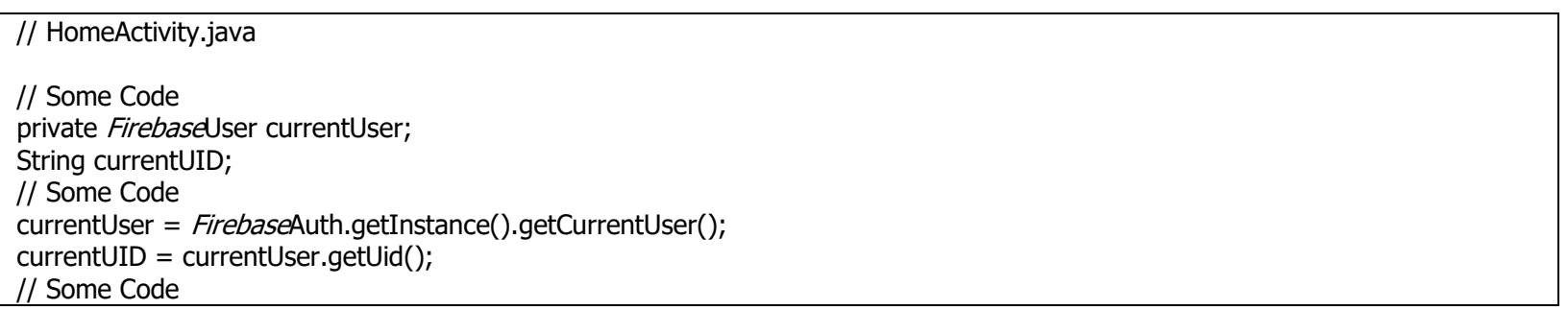

Pada bagian ini, $A P I$ yang digunakan bertujuan untuk mengambil data apakah pengguna telah login atau tidak. Jika tidak ada, maka $A P I$ akan memberhentikan proses karena tidak dapat mendapatkan hasil apakah pengguna sudah login. Setelah API mendapatkan apakah pengguna sudah login atau tidak, selanjutnya aplikasi akan meminta data dari Authentication untuk mengambil User UID. Tujuannya adalah untuk membantu pengambilan data dari Database.

$A P I$ yang digunakan untuk database ada beberapa cara untuk menggunakannya. Berikut beberapa contoh dari penggunaannya.

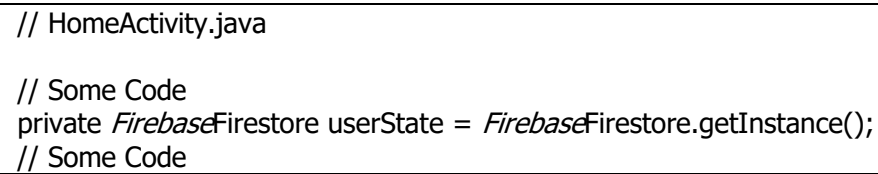


DocumentReference getUserProfile = userState.collection("users").document(currentUID)

getUserProfile.get().addOnSuccessListener(new OnSuccessListener<DocumentSnapshot>() \{

// Some Code

\});

// Some Code

Pada bagian ini $A P I$ yang digunakan bertujuan untuk mengambil data dari database. Jika berhasil, maka aplikasi dapat menampilkan data yang telah diambil dari database. Namun jika terjadi kesalahan, maka $A P I$ akan memberikan respon sesuai dengan apa yang menjadi kendalanya.

\section{Pengujian Sistem}

Sistem yang telah dibentuk atau dibangun akan diuji untuk mengetahui apakah seluruh sistem dapat menghasilkan data yang diinginkan dan sesuai dengan tujuan sistem ini dibentuk. Berikut adalah metode pengujian dari masing-masing sistem yang diuji.

Tabel 1 Metode Pengujian Sistem

\begin{tabular}{|c|c|c|c|}
\hline No. & Sistem yang Diuji & Keterangan & Metode Pengujian \\
\hline \multirow[t]{2}{*}{1} & \multirow[t]{2}{*}{ Halaman selamat datang } & Tombol Registrasi & \multirow[t]{2}{*}{ Black Box } \\
\hline & & Tombol Login & \\
\hline \multirow[t]{2}{*}{2} & \multirow[t]{2}{*}{ Halaman Registrasi } & Tombol Registrasi & \multirow[t]{2}{*}{ Black Box } \\
\hline & & $\begin{array}{ll}\text { Kesalahan } & \text { data } \\
\text { Registrasi } & \end{array}$ & \\
\hline \multirow[t]{2}{*}{3} & \multirow[t]{2}{*}{ Halaman Login } & Tombol Login & \multirow[t]{2}{*}{ Black Box } \\
\hline & & Kesalahan data Login & \\
\hline \multirow[t]{5}{*}{4} & \multirow[t]{5}{*}{ Halaman Utama } & Data Pengguna & \multirow[t]{5}{*}{ Black Box } \\
\hline & & Tombol Transaksi & \\
\hline & & Tombol Transfer & \\
\hline & & Tombol Riwayat & \\
\hline & & Tombol Logout & \\
\hline \multirow[t]{3}{*}{5} & \multirow[t]{3}{*}{ Halaman Menu Transfer } & $\begin{array}{l}\text { Informasi } \quad \text { Barcode } \\
\text { Pengguna }\end{array}$ & \multirow[t]{3}{*}{ Black Box } \\
\hline & & Tombol Next & \\
\hline & & Tombol Back & \\
\hline \multirow[t]{2}{*}{6} & \multirow[t]{2}{*}{ Halaman Transfer } & Tombol Scan Barcode & \multirow[t]{2}{*}{ Black Box } \\
\hline & & Tombol Konfirmasi & \\
\hline \multirow[t]{4}{*}{7} & \multirow[t]{4}{*}{ Halaman Transaksi } & Informasi Scan Barcode & \multirow[t]{4}{*}{ Black Box } \\
\hline & & Tombol Scan Ulang & \\
\hline & & Tombol Text & \\
\hline & & Tombol Back & \\
\hline \multirow[t]{2}{*}{8} & \multirow[t]{2}{*}{ Halaman Riwayat } & Informasi Riwayat & \multirow[t]{2}{*}{ Black Box } \\
\hline & & Tombol Back & \\
\hline
\end{tabular}

Dan berikut ini adalah hasil dari pengujian dari sistem yang menggunakan metode blackbox pada tiap sistem yang diuji.

Tabel 2 Hasil Pengujian Sistem

\begin{tabular}{|l|l|l|l|l|}
\hline No. & Sistem yang Diuji & Proses Uji & Hasil yang Diharapkan & Hasil Pengujian \\
\hline 1 & Halaman selamat datang & $\begin{array}{l}\text { Menekan Tombol } \\
\text { Registrasi }\end{array}$ & $\begin{array}{l}\text { Jika ditekan, akan diarahkan ke } \\
\text { halaman Registrasi }\end{array}$ & "Diterima" \\
\cline { 3 - 5 } & $\begin{array}{l}\text { Menekan Tombol } \\
\text { Login }\end{array}$ & $\begin{array}{l}\text { Jika ditekan, maka diarahkan } \\
\text { ke halaman login }\end{array}$ & "Diterima" \\
\hline 2 & Halaman Registrasi & $\begin{array}{l}\text { Menekan Tombol } \\
\text { Registrasi }\end{array}$ & $\begin{array}{l}\text { Jika ditekan, maka data akan di } \\
\text { simpan ke dalam database dan } \\
\text { pengguna dipindahkan ke } \\
\text { halaman login }\end{array}$ & "Diterima" \\
\hline
\end{tabular}




\begin{tabular}{|c|c|c|c|c|}
\hline & & $\begin{array}{l}\text { Kesalahan data } \\
\text { Registrasi }\end{array}$ & $\begin{array}{l}\text { Jika data yang di-input kosong } \\
\text { atau kurang, akan muncul } \\
\text { peringatan kesalahan }\end{array}$ & "Diterima" \\
\hline \multirow[t]{2}{*}{3} & \multirow[t]{2}{*}{ Halaman Login } & $\begin{array}{l}\text { Menekan Tombol } \\
\text { Login }\end{array}$ & $\begin{array}{l}\text { Jika data yang di-input benar, } \\
\text { maka akan diarahkan ke } \\
\text { halaman utama }\end{array}$ & "Diterima" \\
\hline & & $\begin{array}{l}\text { Kesalahan data } \\
\text { Login }\end{array}$ & $\begin{array}{l}\text { Jika data yang di-input kosong } \\
\text { atau salah, maka akan muncul } \\
\text { peringatan. }\end{array}$ & "Diterima" \\
\hline \multirow[t]{5}{*}{4} & \multirow[t]{5}{*}{ Halaman Utama } & $\begin{array}{l}\text { Menampilkan Data } \\
\text { Pengguna }\end{array}$ & $\begin{array}{l}\text { Akan muncul data pengguna } \\
\text { yang login }\end{array}$ & "Diterima" \\
\hline & & $\begin{array}{l}\text { Menekan Tombol } \\
\text { Transaksi }\end{array}$ & $\begin{array}{l}\text { Jika ditekan, maka akan } \\
\text { diarahkan ke halaman } \\
\text { transaksi. }\end{array}$ & "Diterima" \\
\hline & & $\begin{array}{l}\text { Menekan Tombol } \\
\text { Transfer }\end{array}$ & $\begin{array}{l}\text { Jika ditekan, maka akan } \\
\text { diarahkan ke halaman transfer }\end{array}$ & "Diterima" \\
\hline & & $\begin{array}{l}\text { Menekan Tombol } \\
\text { Riwayat }\end{array}$ & $\begin{array}{l}\text { Jika ditekan, maka akan } \\
\text { diarahkan ke halaman riwayat. }\end{array}$ & "Diterima" \\
\hline & & $\begin{array}{l}\text { Menekan Tombol } \\
\text { Logout }\end{array}$ & $\begin{array}{l}\text { Jika ditekan, maka pengguna } \\
\text { yang sedang login, akan } \\
\text { diarahkan ke halaman login. }\end{array}$ & "Diterima" \\
\hline \multirow[t]{3}{*}{5} & \multirow[t]{3}{*}{ Halaman Menu Transfer } & $\begin{array}{l}\text { Informasi Barcode } \\
\text { Pengguna }\end{array}$ & $\begin{array}{l}\text { Akan menampilkan barcode } \\
\text { yang sesuai dengan pengguna } \\
\text { yang sedang login }\end{array}$ & "Diterima" \\
\hline & & $\begin{array}{l}\text { Menekan Tombol } \\
\text { Next }\end{array}$ & $\begin{array}{l}\text { Jika ditekan, akan diarahkan ke } \\
\text { halaman transfer selanjutnya }\end{array}$ & "Diterima" \\
\hline & & $\begin{array}{l}\text { Menekan Tombol } \\
\text { Back }\end{array}$ & $\begin{array}{l}\text { Jika ditekan, akan diarahkan ke } \\
\text { halaman sebelumnya. }\end{array}$ & "Diterima" \\
\hline \multirow[t]{2}{*}{6} & \multirow[t]{2}{*}{ Halaman Transfer } & $\begin{array}{l}\text { Tombol Scan } \\
\text { Barcode }\end{array}$ & $\begin{array}{l}\text { Jika ditekan, maka akan } \\
\text { melakukan scan barcode dan } \\
\text { melakukan scan }\end{array}$ & "Diterima" \\
\hline & & $\begin{array}{l}\text { Menekan Tombol } \\
\text { Konfirmasi }\end{array}$ & $\begin{array}{l}\text { Setelah memasukkan nominal } \\
\text { yang akan ditransfer, maka } \\
\text { data transfer akan dicatat dan } \\
\text { kembali ke halaman utama. }\end{array}$ & "Diterima" \\
\hline \multirow[t]{2}{*}{7} & \multirow[t]{2}{*}{ Halaman Transaksi } & $\begin{array}{l}\text { Tombol } \quad \text { Scan } \\
\text { Barcode }\end{array}$ & $\begin{array}{l}\text { Jika ditekan, maka akan } \\
\text { melakukan scan barcode dan } \\
\text { melakukan scan }\end{array}$ & "Diterima" \\
\hline & & $\begin{array}{l}\text { Menekan Tombol } \\
\text { Konfirmasi }\end{array}$ & $\begin{array}{l}\text { Setelah memasukkan nominal } \\
\text { yang akan dibayar, maka data } \\
\text { transaksi akan dicatat dan } \\
\text { kembali ke halaman utama. }\end{array}$ & "Diterima" \\
\hline \multirow[t]{2}{*}{8} & \multirow[t]{2}{*}{ Halaman Riwayat } & Informasi Riwayat & $\begin{array}{l}\text { Data riwayat yang telah } \\
\text { dilakukan oleh pengguna, akan } \\
\text { ditampilkan }\end{array}$ & "Ditolak" \\
\hline & & $\begin{array}{l}\text { Menekan Tombol } \\
\text { Back }\end{array}$ & $\begin{array}{l}\text { Jika ditekan, maka akan } \\
\begin{array}{l}\text { diarahkan ke halaman } \\
\text { sebelumnya }\end{array}\end{array}$ & "Diterima" \\
\hline
\end{tabular}

Menurut hasil pengujian yang dilakukan, maka penulis mendapat kesimpulan bahwa secara dominan sistem berjalan sesuai dengan fungsinya dan dapat mengirim dan menerima data yang diminta.

\section{Pembahasan/Kesimpulan}

Berdasarkan analisa, perancangan dan pengujian yang telah dilakukan di Universitas Advent Indonesia berdasarkan bab sebelumnya, maka dapat disimpulkan bahwa: 1 . Aplikasi pembayaran yang sudah dibuat 
Perancangan Sistem Transaksi Non-Tunai Berbasis QR Code di Platform Android

dapat digunakan melalui Smartphone berbasis Android. 2. Aplikasi pembayaran yang sudah dibuat dapat memenuhi kebutuhan yang ada seperti pembayaran, transfer dan melihat riwayat. 3. Aplikasi pembayaran yang sudah dirancang belum dapat memberikan beberapa data atau informasi yang holistik kepada pengguna dan terdapat beberapa fungsi yang sudah dibuat, namun belum dapat memberikan hasil yang sesuai dengan kebutuhan.

Untuk pembaca, pengguna dan pengembang sistem ke depannya agar dapat: 1. Diharapkan untuk pengembang selanjutnya, dapat mengembangkan User Interface dan User Experience yang lebih baik. 2. Karena aplikasi yang dibuat menggunakan Database NonSQL, maka banyak hal yang harus diubah seperti penstrukturan data dan jenis data yang akan disimpan. 3. Untuk penelitian selanjutnya diharapkan peneliti

menggunakan React-Native atau Expo-cli hal ini disebabkan karena versi dari React-Native berkembang dengan pesat. Disarankan untuk peneliti selanjutnya, dapat memperhatikan setiap perubahan yang terjadi. 4. Menambahkan fungsi keamanan dari sistem transaksi agar semakin lengkap.

\section{Referensi}

[1] J. Hutahean, Konsep Sistem Informasi, Yogyakarta: Deepublish Publisher, 2015.

[2] T. Sutabri, Konsep Sistem Informasi, Bandung: Penerbit Andi, 2012.

[3] S. F. Saragih and E. B. Wagiu, "Analisa Perencanaan Pembayaran Menggunakan Sistem $Q R$ Code di Industrial Universitas Advent Indonesia," TeIKa, vol. 09, no. 01, pp. 15-29, Oktober 2019.

[4] J. I. Sihotang, "Perancangan Sistem Transaksi Berbasis Near Field Communication (NFC) Dengan Sistem Operasi Android di Toko Virtual," in Konferensi Nasional Sistem Informasi, Makassar, 2014.

[5] B. F. M. Sitompul, T. W. Krisna and V. W. J. Supit, Perancangan Sistem Informasi MYUNAI Berbasis Mobile Application Android dan IOS Menggunakan Framework React Native, Bandung: Fakultas Teknologi Informasi Universitas Advent Indonesia, 2019.

[6] L. Collins and S. R. Ellis, Mobile Devices: Tools and Technologies, UK: CRC Press, 2015.

[7] R. Singh, "An Overview of Android Operating System and Its Security," Int. Journal of Engineering Research and Applications, vol. 4, no. 2, pp. 519-521, 2014.

[8] H. M. Christon, Perancangan Sistem E-Learning Berbasis Android, Bandung: Fakultas Teknologi Informasi Universitas Advent Indonesia, 2017.

[9] M. Ohyver, J. V. Moniaga, I. Sungkawa, B. E. Subagyo and I. A. Chandra, "The Comparison Firebase Realtime Database and MySQL Database Performance using Wilcoxon Signed-Rank Test," Procedia Computer Science, vol. 157, pp. 396-405, 2019.

[10] A. Qashlim and Hasruddin, "Implementasi Teknologi QR-Code untuk Kartu Identitas," Jurnal IImiah IImu Komputer, vol. 1, no. 2, pp. 1-6, 2015.

[11] R. Susanto and A. Andriana, "PERBANDINGAN MODEL WATERFALL DAN PROTOTYPING UNTUK PENGEMBANGAN SISTEM INFORMASI," Majalah IImiah UNIKOM, vol. 14, no. 1, p. 174, 2016.

[12] T. S. Jaya and D. Sahlinal, "Perancangan Kantor Digital Berbasis Framework dengan Metode Waterfal/pada Politeknik Negeri Lampung," Jurnal Informatika: Jurnal Pengembangan IT, vol. z no. 2, pp. 14-17, 2017.

[13] Google, "Firebase," Google, 2020. [Online]. Available: https://firebase.google.com/. [Accessed 2020 Januari 07]. 